\title{
Janeway Lesions: a Painless Manifestation of Infective Endocarditis
}

\author{
Sreelakshmi Panginikkod, $\mathrm{MD}^{7}$, Venu Gopalakrishnan, $\mathrm{MD}^{7}$, Malav Parikh, $\mathrm{MD}^{2}$, and \\ Niyati Gupta, MBBS ${ }^{2}$ \\ 'Department of Internal Medicine, Presence Saint Francis Hospital, Evanston, IL, USA; ${ }^{2}$ Division of Hospital Medicine, Cleveland Clinic Foundation, \\ Cleveland, $\mathrm{OH}$, USA.
}

KEY WORDS: Janeway lesion; infective endocarditis; mitral valve abscess; clinical signs in endocarditis; methicillin-sensitive staph aureus.

J Gen Intern Med 34(7):1360-1

DOI: $10.1007 / \mathrm{s} 11606-018-4770-6$

(c) Society of General Internal Medicine 2018

\section{CLINICAL IMAGE TEXT DESCRIPTION}

A 74-year-old woman presented with fatigue and worsening dyspnea. On examination, she was febrile, tachycardic, and tachypneic, with a pansystolic murmur. A painless erythematous nodule was noted on her right hypothenar eminence (Fig. 1). Chest x-ray showed bilateral ill-defined airspace opacities. Blood culture grew methicillin-sensitive Staphylococcus aureus. Transesophageal echocardiography revealed an abscess on the posterior mitral leaflet (Fig. 2), confirming the diagnosis of infective endocarditis.

Janeway lesions and Osler's nodes are both classic stigmata of endocarditis, but distinguishing the two can be difficult. Janeway lesions are nontender hemorrhagic macules or papules located on palms, soles, and thenar and hypothenar eminences. Osler's nodes are painful violaceous nodes typically found on fingers and toes.

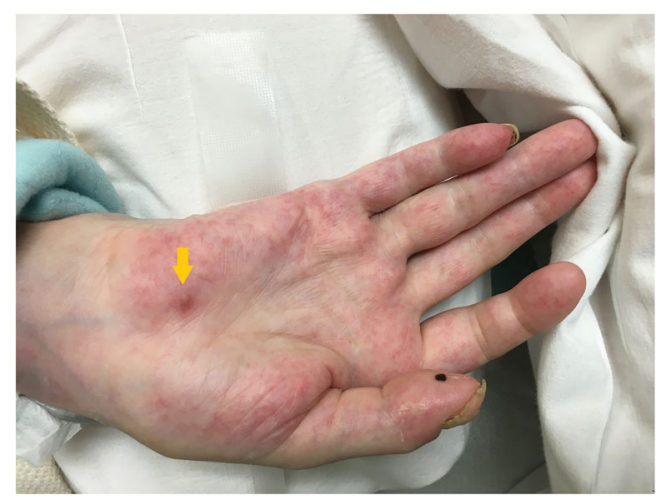

Figure 1 Photograph showing a Janeway lesion on right hypothenar eminence.
Traditionally, Janeway lesions have been attributed to septic emboli and Osler's nodes described as an immunologic phenomenon. However, histologic evaluation of the two shows significant overlap. Both have been associated with neutrophilic vasculitis, microabscesses, and pathologic organism on culture. ${ }^{1-3}$ The most widely agreed upon difference between Janeway lesions and Osler's nodes is that the former is painless, whereas the latter is painful. ${ }^{2}$ Classic skin manifestations of infective endocarditis are associated with a higher risk of complications and remain an important clinical finding. ${ }^{3}$

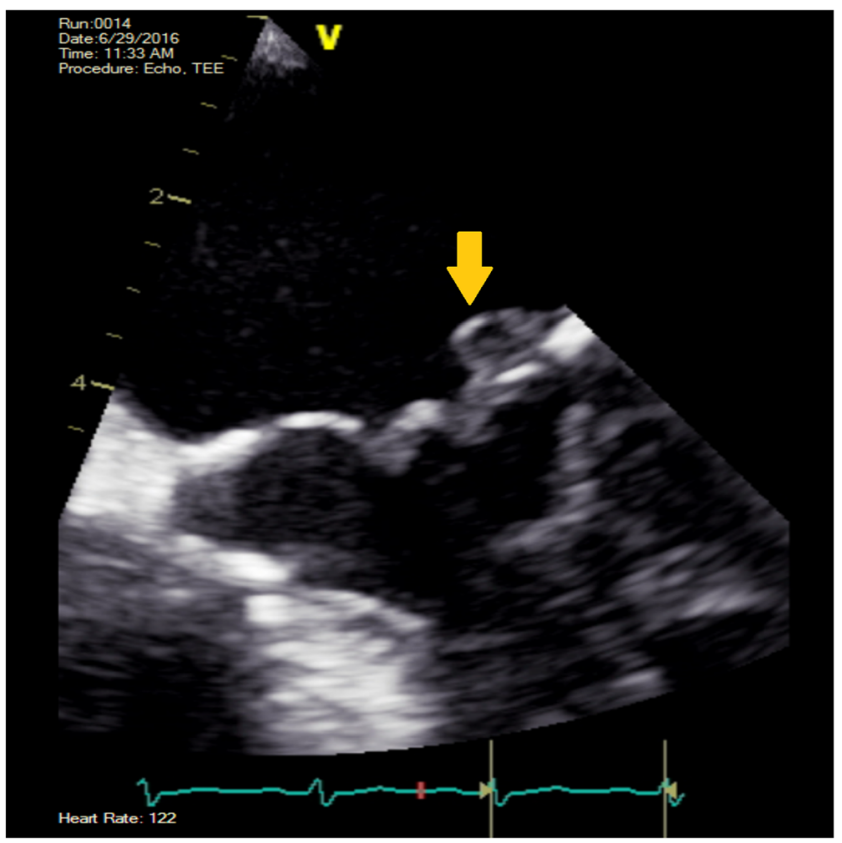

Figure 2 Transesophageal echocardiogram showing a cystic structure on the posterior mitral leaflet, suggestive of an abscess.

Corresponding Author: Sreelakshmi Panginikkod, MD; Department of Internal Medicine, Presence Saint Francis Hospital, Evanston, IL, USA (e-mail: sreelakshmi.panginikkod@presencehealth.org).

Received January 2, 2018

Revised February 16, 2018

Accepted November 21, 2018

Published online April 18, 2019 


\section{Compliance with Ethical Standards:}

Conflict of Interest: The authors of this manuscript certify that they have no affiliations with or involvement in any organization or entity with any financial or non-financial interest in the subject matter or materials discussed in this manuscript.

\section{REFERENCES}

1. Gunson TH, Oliver GF. Osler's nodes and Janeway lesions. Australas J Dermatol. 2007:48(4):251-5.
2. Farrior JB, Silverman ME. A consideration of the differences between a Janeway's lesion and an Osler's node in infectious endocarditis. Chest. 1976;70(2):239-43.

3. Servy A, Valeyrie-Allanore L, Alla F, Lechiche C, Nazeyrollas P, Chidiac C, et al. Prognostic value of skin manifestations of infective endocarditis. JAMA Dermatol. 2014;150(5):494-500.

Publisher's Note Springer Nature remains neutral with regard to jurisdictional claims in published maps and institutional affiliations. 